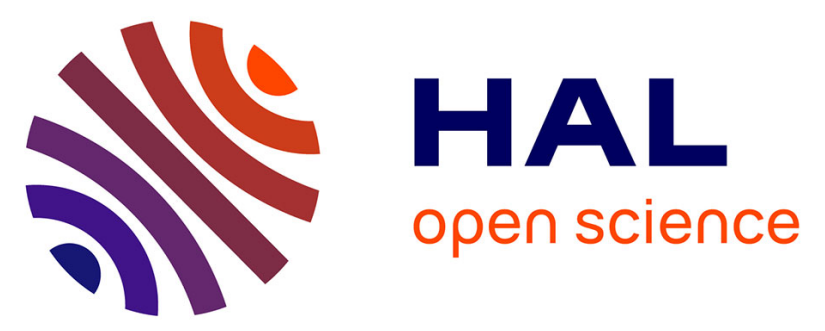

\title{
Oxidation Behavior of the Skutterudite Material Yb0.2Co4Sb12
}

Richard Drevet, Lionel Aranda, Nicolas David, Mohamed Benyahia, Driss

Kenfaui, Philippe Masschelein, Christophe Candolfi, Bertrand Lenoir, Judith Monnier, Anne Dauscher, et al.

\section{To cite this version:}

Richard Drevet, Lionel Aranda, Nicolas David, Mohamed Benyahia, Driss Kenfaui, et al.. Oxidation Behavior of the Skutterudite Material Yb0.2Co4Sb12. Metallurgical and Materials Transactions A, 2021, 52 (9), pp.3996-4002. 10.1007/s11661-021-06359-6 . hal-03409569

\section{HAL Id: hal-03409569 https://hal.science/hal-03409569}

Submitted on 29 Oct 2021

HAL is a multi-disciplinary open access archive for the deposit and dissemination of scientific research documents, whether they are published or not. The documents may come from teaching and research institutions in France or abroad, or from public or private research centers.
L'archive ouverte pluridisciplinaire HAL, est destinée au dépôt et à la diffusion de documents scientifiques de niveau recherche, publiés ou non, émanant des établissements d'enseignement et de recherche français ou étrangers, des laboratoires publics ou privés. 


\title{
Oxidation Behavior of the Skutterudite Material $\mathrm{Yb}_{0.2} \mathrm{Co}_{4} \mathrm{Sb}_{12}$
}

\author{
RICHARD DREVET, LIONEL ARANDA, NICOLAS DAVID, \\ MOHAMED BENYAHIA, DRISS KENFAUI, PHILIPPE MASSCHELEIN, \\ CHRISTOPHE CANDOLFI, BERTRAND LENOIR, JUDITH MONNIER, \\ ANNE DAUSCHER, ERIC ALLENO, and PATRICE BERTHOD
}

The skutterudite materials belonging to the $\mathrm{CoSb}_{3}$ family are widely studied for thermoelectric applications. They are typically used under vacuum, but applications under oxidizing environments are increasingly considered. The addition of ytterbium is known to enhance the thermoelectric properties of $\mathrm{CoSb}_{3}$, but the corresponding impact on the oxidation behavior of the skutterudite material is barely explored. For that purpose, the present research describes the oxidation behavior of $\mathrm{Yb}_{0.2} \mathrm{Co}_{4} \mathrm{Sb}_{12}$ under a flow of air at $800 \mathrm{~K}$ for $15,50,100$, and 1000 hours. The oxidation treatment induces the growth of a surface layer made of three oxides in various amounts as a function of the oxidation time. The spinel oxide $\mathrm{CoSb}_{2} \mathrm{O}_{4} / \mathrm{CoO} \cdot \mathrm{Sb}_{2} \mathrm{O}_{3}$ and $\mathrm{CoSb}_{2} \mathrm{O}_{6}$ are observed from 15 hours of oxidation, whereas $\mathrm{Sb}_{2} \mathrm{O}_{4}$ is formed only from 100 hours of treatment. To assess the impact of ytterbium, the oxidation behavior of $\mathrm{Yb}_{0.2} \mathrm{Co}_{4} \mathrm{Sb}_{12}$ is compared to that of $\mathrm{CoSb}_{3}$ oxidized in the same experimental conditions. The results show that the low amount of ytterbium promotes the oxidation reactions of the skutterudite material. Nonetheless, the impact on the degradation of the material remains acceptable to use $\mathrm{Yb}_{0.2} \mathrm{Co}_{4} \mathrm{Sb}_{12}$ for thermoelectric applications under oxidizing environments.

https://doi.org/10.1007/s11661-021-06359-6

(C) The Minerals, Metals \& Materials Society and ASM International 2021

\section{INTRODUCTION}

THE skutterudite compounds are thermoelectric materials, i.e., materials with the ability to produce electrical energy from heat flow. ${ }^{[1-5]}$ Among them, $\mathrm{CoSb}_{3}$ is currently the most employed one to produce the electrical generators used for space explorations thanks to powerful thermoelectric properties such as a high figure of merit and a good Seebeck coefficient. ${ }^{[6-9]}$ Although these properties are valuable, the enhancement of skutterudite materials remains an actual challenge for research and industry. Many recent developments describe the positive impact of filling atoms inside the crystal lattice of $\mathrm{CoSb}_{3} \cdot{ }^{[10-12]}$ Particularly, the addition of ytterbium is established to improve

RICHARD DREVET, LIONEL ARANDA, NICOLAS DAVID, DRISS KENFAUI, PHILIPPE MASSCHELEIN, CHRISTOPHE CANDOLFI, BERTRAND LENOIR, ANNE DAUSCHER, and PATRICE BERTHOD are with the Institut Jean Lamour, CNRS Université de Lorraine, UMR 7198, Campus Artem, allée André Guinier, BP 50840, 54011 Nancy cedex, France. Contact e-mail: richarddrevet@yahoo.fr MOHAMED BENYAHIA, ERIC ALLENO and JUDITH MONNIER are with the CNRS UMR 7182, ICMPECMTR, 2-8 rue H. Dunant, 94320 Thiais, France

Manuscript submitted on December 31, 2020; accepted June 8, 2021. the thermoelectric properties by reducing the lattice thermal conductivity and by promoting the n-type conduction, thus improving the figure of merit of the skutterudite material. ${ }^{[13,14]}$ Nowadays, the most interesting skutterudite material containing ytterbium is $\mathrm{Yb}_{0.2} \mathrm{Co}_{4} \mathrm{Sb}_{12}{ }^{[15,16]}$

As efficient electrical energy producers, the skutterudite materials are increasingly considered to produce generators usable on Earth, i.e., under oxidizing environments. ${ }^{[17,18]}$ To reach this objective, the impact of ytterbium on the oxidation behavior of the skutterudite material must be carefully assessed. Indeed, the oxidation behavior of metallic materials can be significantly affected by any chemical or structural modifications. ${ }^{[19]}$ In service, the skutterudite materials typically face temperatures of hundreds of kelvins that potentially induce permanent damages. ${ }^{[17]}$ The corresponding oxidation reactions may degrade the thermoelectric properties of the material and the durability of the device. ${ }^{[1-5]}$ Ideally, for potential industrial applications, the skutterudite materials have to successfully resist for thousands of hours in air at $800 \mathrm{~K}$, a relevant temperature found for example in car exhaust gases. ${ }^{[18-20]}$ If this key objective is reached, $\mathrm{Yb}_{0.2} \mathrm{Co}_{4} \mathrm{Sb}_{12}$ will be established to be an efficient skutterudite material to produce the next generation of electrical generators. 
In that framework, this research work explores the oxidation behavior of $\mathrm{Yb}_{0.2} \mathrm{Co}_{4} \mathrm{Sb}_{12}$ at $800 \mathrm{~K}$, to assess the potential use of this innovative skutterudite material under oxidizing environments. The surface changes induced by the oxidation treatment are described and discussed. The results are compared with those obtained for $\mathrm{CoSb}_{3}$ oxidized in the same experimental conditions.

\section{MATERIALS AND METHODS}

\section{A. Synthesis of Skutterudite Materials}

The skutterudite material $\mathrm{Yb}_{0.2} \mathrm{Co}_{4} \mathrm{Sb}_{12}$ is synthesized according to the protocol developed in our labs. ${ }^{[11,12,21-23]}$ Briefly, a stoichiometric mixture of high purity powders of ytterbium (Yb, 99.99 pct), cobalt (Co, $99.99 \mathrm{pct}$ ), and antimony ( $\mathrm{Sb}, 99.999 \mathrm{pct}$ ) is melted at $1373 \mathrm{~K}$ for 24 hours, then annealed at $1093 \mathrm{~K}$ for 96 hours under argon atmosphere inside a vitreous-carbon crucible. The obtained button is thoroughly crushed to produce a powder densified by spark plasma sintering (SPS, Syntex DR SINTER Lab 515S) in graphite dies for 10 minutes at $893 \mathrm{~K}$ under $50 \mathrm{MPa}$. The same protocol is used for the synthesis of $\mathrm{CoSb}_{3}$ samples.

\section{B. Preparation and Oxidation of Skutterudite Materials}

The skutterudite samples are slightly polished and ultrasonically cleaned in ethanol. The oxidation treatments are carried out inside a tube furnace (Carbolite) under a continuous flow of synthetic air $\left(4 \mathrm{~L} \mathrm{~h}^{-1}\right)$. The samples are oxidized at $800 \mathrm{~K}$ for $15,50,100$, or 1000 hours.

\section{Characterization of Skutterudite Materials}

The crystalline phases of the oxidized samples are characterized by X-ray diffraction (XRD) with a Philips X'pert Pro diffractometer using monochromatic $\mathrm{Cu}_{\mathrm{K} \alpha}$ radiation $(\lambda=0.15406 \mathrm{~nm})$. The phases are identified from the diffraction files provided by the International Centre for Diffraction Data (ICDD). A scanning electron microscope (SEM, JEOL JSM 6010LA) is used to study the surface morphology of the samples from secondary electrons (SE) and their cross-sections from backscattered electrons (BSE). This SEM is equipped with an energy dispersive X-ray spectrometer (EDS). At last, the mass variation $(\Delta m)$ of the oxidized samples is measured as a function of their oxidation time with a precision balance (METTLER-TOLEDO).

\section{RESULTS AND DISCUSSION}

The skutterudite materials $\mathrm{Yb}_{0.2} \mathrm{Co}_{4} \mathrm{Sb}_{12}$ and $\mathrm{CoSb}_{3}$ were oxidized in air at $800 \mathrm{~K}$ for $15,50,100$, and 1000 hours. The corresponding surface oxides are identified for both samples from the XRD patterns of Figures 1 and 2 , respectively.
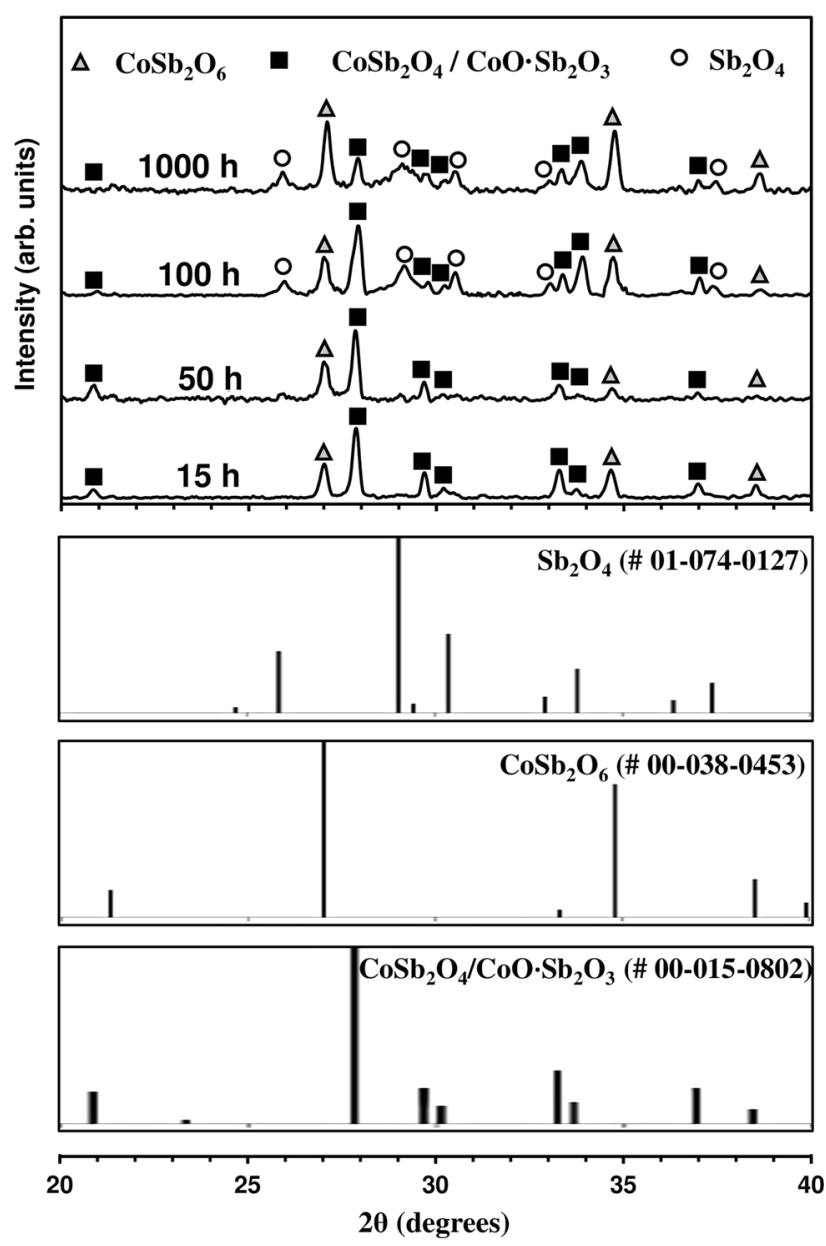

Fig. 1-XRD pattern of $\mathrm{Yb}_{0.2} \mathrm{Co}_{4} \mathrm{Sb}_{12}$ as a function of oxidation time in air at $800 \mathrm{~K}$.

Three oxides of cobalt and/or antimony are identified in various amounts depending on the oxidation time. The signal from the spinel oxide $\mathrm{CoSb}_{2} \mathrm{O}_{4} / \mathrm{CoO} \cdot \mathrm{Sb}_{2} \mathrm{O}_{3}$ is the main one, identified from 15 hours of oxidation. ${ }^{[24,25]}$ The signal from $\mathrm{CoSb}_{2} \mathrm{O}_{6}$ increases with the oxidation time, appearing from 100 hours of oxidation in the case of $\mathrm{CoSb}_{3}$, whereas it is already present from 15 hours of oxidation in the case of $\mathrm{Yb}_{0.2} \mathrm{Co}_{4} \mathrm{Sb}_{12}$. The signal from the skutterudite is observed during the first times of oxidation in the case of $\mathrm{CoSb}_{3}$, whereas only the oxides are identified in the case of $\mathrm{Yb}_{0.2} \mathrm{Co}_{4} \mathrm{Sb}_{12}$, even at 15 hours of oxidation. The third oxide is $\mathrm{Sb}_{2} \mathrm{O}_{4}$ whose signal is detected from 100 hours of oxidation for both samples and becomes higher after 1000 hours of treatment. The production of $\mathrm{Sb}_{2} \mathrm{O}_{4}$ during the oxidation of $\mathrm{CoSb}_{3}$ samples in air at $800 \mathrm{~K}$ is commonly described in two steps according to the following reactions ${ }^{[26]}$ :

$$
\begin{aligned}
4 \mathrm{CoSb}_{3}(\mathrm{~s})+11 \mathrm{O}_{2}(\mathrm{~g})= & 4 \mathrm{CoSb}_{2} \mathrm{O}_{4}(\mathrm{~s}) \\
& +2 \mathrm{Sb}_{2} \mathrm{O}_{3}(\mathrm{~s}) \\
& \\
4 \mathrm{Sb}_{2} \mathrm{O}_{3}(\mathrm{~s}) \rightarrow 2 / \mathrm{n} \mathrm{Sb}_{\mathrm{n}}(\mathrm{g})+ & 3 \mathrm{Sb}_{2} \mathrm{O}_{4}(\mathrm{~s})
\end{aligned}
$$



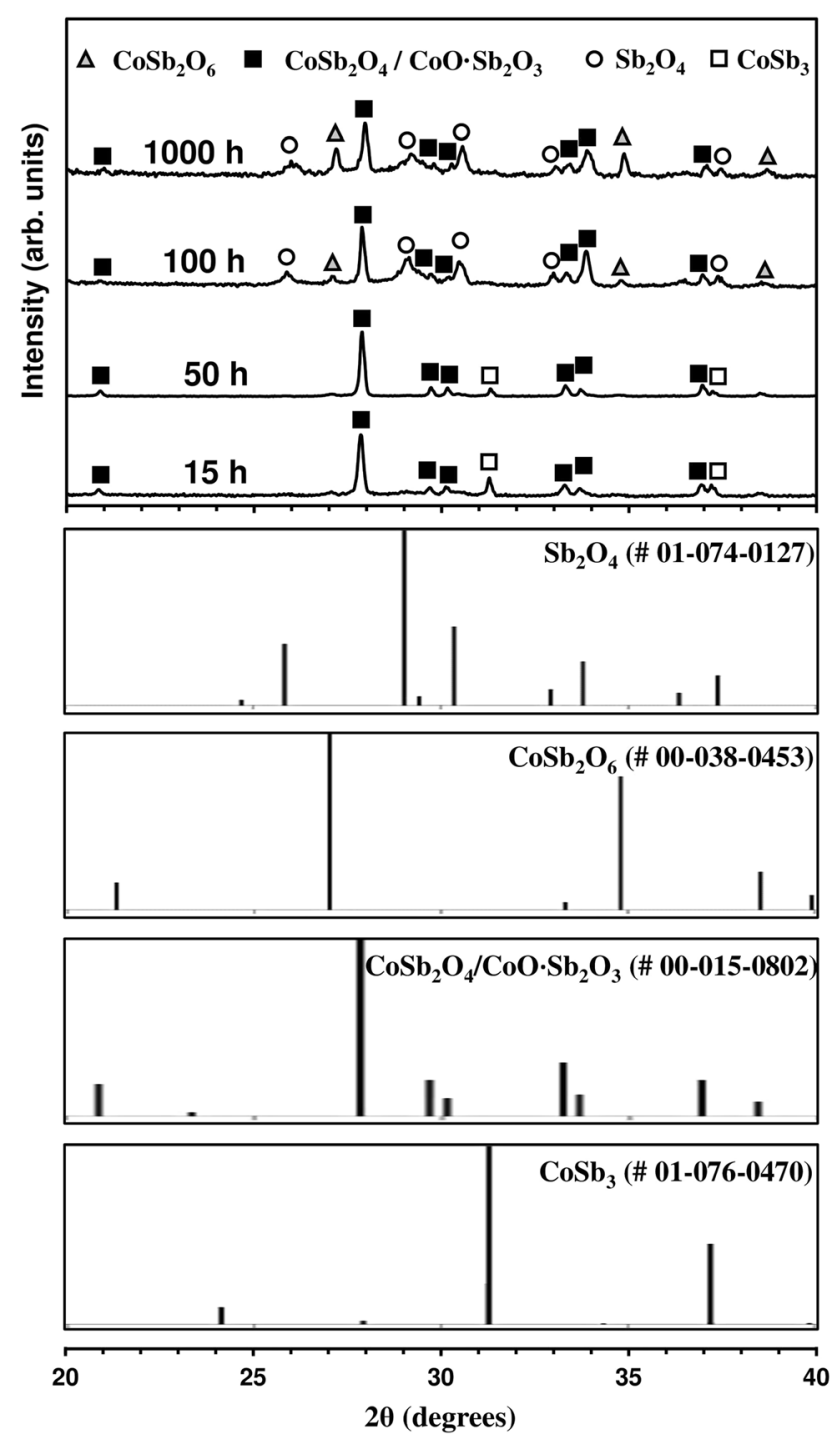

Fig. 2-XRD pattern of $\mathrm{CoSb}_{3}$ as a function of oxidation time in air at $800 \mathrm{~K}$. Reprinted with permission from Ref. 23.

These oxidation reactions are undoubtedly the same in the case of $\mathrm{Yb}_{0.2} \mathrm{Co}_{4} \mathrm{Sb}_{12}$ samples. The oxide $\mathrm{CoSb}_{2} \mathrm{O}_{4}$ may be oxidized, producing $\mathrm{CoSb}_{2} \mathrm{O}_{6}$ according to reaction $[3]^{[27]}$ :

$$
\mathrm{CoSb}_{2} \mathrm{O}_{4}(\mathrm{~s})+\mathrm{O}_{2}(\mathrm{~g}) \rightarrow \mathrm{CoSb}_{2} \mathrm{O}_{6}(\mathrm{~s})
$$

These reactions induce the surface changes presented on the SEM images of Figures 3 and 4, showing the progressive growth of the oxide layers with the oxidation time. These surface layers are made of crystallites the size of which increases all along the 1000 hours of treatment. The morphologies of these surface oxide layers look similar, but the crystallites are larger in the case of $\mathrm{Yb}_{0.2} \mathrm{Co}_{4} \mathrm{Sb}_{12}$, regardless of the oxidation time.

The corresponding mass variations are plotted as a function of the oxidation time in Figure 5. The two curves have similar behaviors, growing as a function of the square root of time. According to Fick's law, the main models of oxidation of metals and alloys describe a

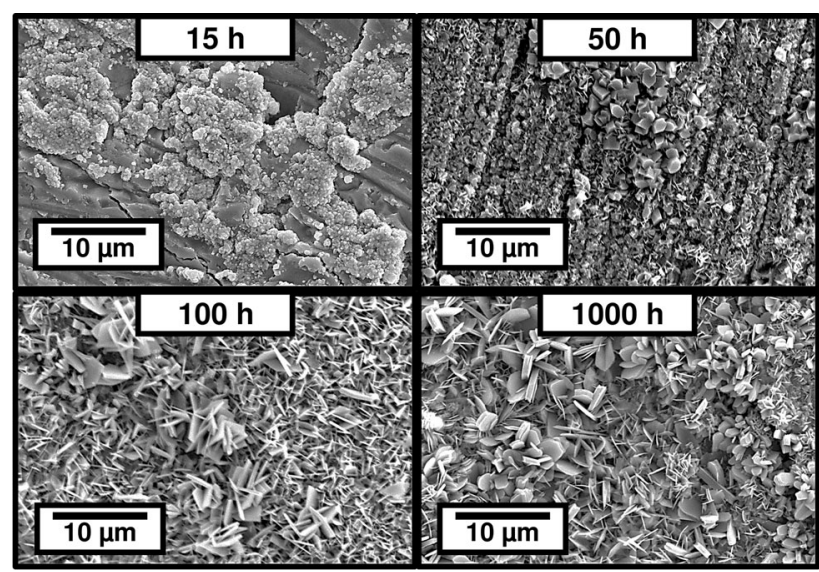

Fig. 3-SEM images (secondary electrons) of the surface of $\mathrm{Yb}_{0.2} \mathrm{Co}_{4} \mathrm{Sb}_{12}$ as a function of oxidation time in air at $800 \mathrm{~K}$.

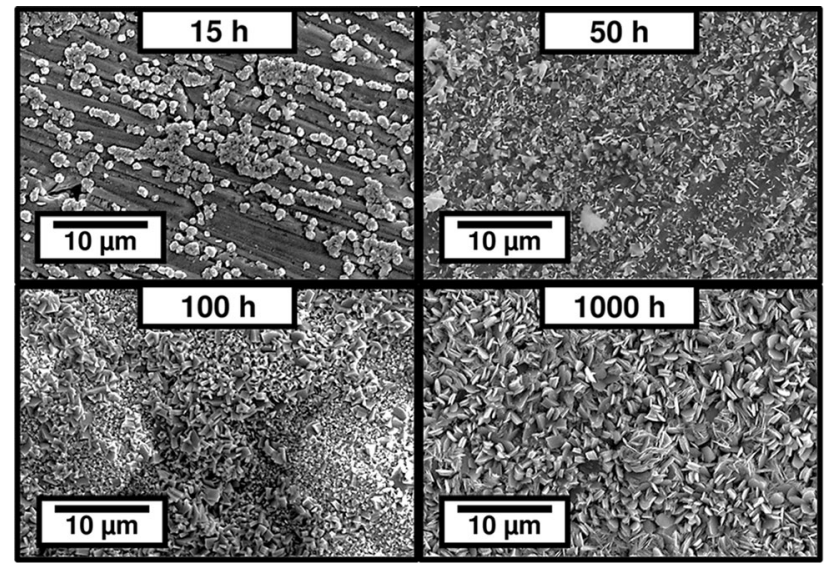

Fig. 4-SEM images (secondary electrons) of the surface of $\mathrm{CoSb}_{3}$ as a function of oxidation time in air at $800 \mathrm{~K}$.

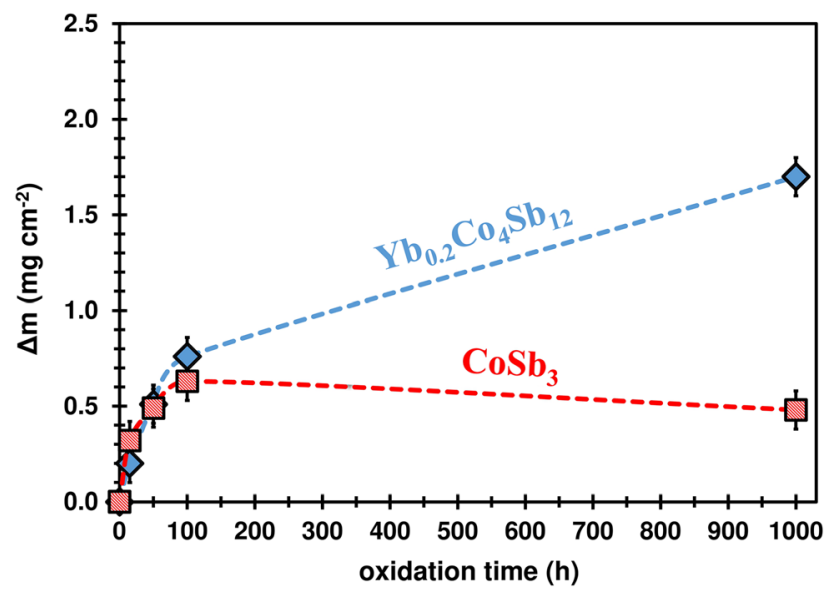

Fig. 5-Mass variation of $\mathrm{Yb}_{0.2} \mathrm{Co}_{4} \mathrm{Sb}_{12}$ and $\mathrm{CoSb}_{3}$ as a function of oxidation time in air at $800 \mathrm{~K}$.

diffusion-controlled process. ${ }^{[28,29]}$ The oxidation reactions occur either by the diffusion of metal ions towards the surface to react with oxygen or by the diffusion of oxygen ions through the oxide layer to react with metal ions at the metal/oxide interface. ${ }^{[30]}$ As the oxide layer 
growth continues with time, the diffusing species take a longer time to reach the surface or the metal/oxide interface, progressively slowing down the oxidation process. ${ }^{[31]}$ The first times of oxidation are similar for both samples, but from 100 hours of oxidation, the mass of $\mathrm{CoSb}_{3}$ slightly decreases whereas that of $\mathrm{Yb}_{0.2} \mathrm{Co}_{4} \mathrm{Sb}_{12}$ is still increasing. Indeed, it is well established in the literature that the oxidation of skutterudite materials combines several phenomena, being not only diffusion-controlled as typically described for metallic alloys. ${ }^{[32]}$

During the oxidation treatment, the formation of oxides induces a mass gain and the growth of a surface layer as described from the images of Figures 3 and 4. However, the simultaneous evaporation of several chemical species also contributes to the mass variation of the samples. According to reaction (2), the sublimation of antimony from the substrate occurs simultaneously with the formation of $\mathrm{Sb}_{2} \mathrm{O}_{4}$. Moreover, several studies also demonstrate that $\mathrm{CoSb}_{3}$ is decomposed from $800 \mathrm{~K}$ producing a mixture of $\mathrm{CoSb}_{2}$ and $\mathrm{CoSb}$ together with volatile antimony according to Reactions $[4]$ and $[5]^{[27,33]}$ :

$$
\begin{aligned}
& \mathrm{CoSb}_{3}(\mathrm{~s}) \rightarrow \mathrm{CoSb}_{2}(\mathrm{~s})+1 / 4 \mathrm{Sb}_{4}(\mathrm{~g}) \\
& \mathrm{CoSb}_{2}(\mathrm{~s}) \rightarrow \mathrm{CoSb}(\mathrm{s})+1 / 4 \mathrm{Sb}_{4}(\mathrm{~g})
\end{aligned}
$$

At last, the volatilization of some unstable oxide phases (e.g., $\mathrm{Sb}_{2} \mathrm{O}_{3}, \mathrm{Sb}_{4} \mathrm{O}_{6}$ ) also influences the oxidation behavior of the skutterudite materials. ${ }^{[26]}$ However, after 1000 hours of oxidation, it is noticeable that the mass gain of $\mathrm{Yb}_{0.2} \mathrm{Co}_{4} \mathrm{Sb}_{12}$ is higher than that of $\mathrm{CoSb}_{3}$. This observation means that the low amount of ytterbium added to the skutterudite promotes the formation of stable oxides rather than volatile species. Indeed, the atomic radius of ytterbium $\left(r_{(\mathrm{Yb})}=1.76 \AA\right)$ is larger than those of cobalt $\left(r_{(\mathrm{Co})}=1.25 \AA\right)$ and antimony $\left(r_{(\mathrm{Sb})}\right.$ $=1.38 \AA) .{ }^{[34]}$ The corresponding crystal lattice distortion weakens the bonds between $\mathrm{Co}$ and $\mathrm{Sb}$ in the skutterudite material, promoting the diffusion of oxygen and increasing the formation of stable oxidation products. $^{[14]}$ All along the oxidation treatment, the XRD patterns of the oxidized $\mathrm{Yb}_{0.2} \mathrm{Co}_{4} \mathrm{Sb}_{12}$ (Figure 1) show higher signals of $\mathrm{CoSb}_{2} \mathrm{O}_{6}$ than those observed from the XRD patterns of the oxidized $\mathrm{CoSb}_{3}$ (Figure 2). According to reaction (3), $\mathrm{CoSb}_{2} \mathrm{O}_{6}$ is produced by the oxidation of $\mathrm{CoSb}_{2} \mathrm{O}_{4}$, which is formed first during the oxidation of the skutterudite materials. ${ }^{[27]}$ This reaction is promoted by the presence of ytterbium that promotes the inward diffusion of oxygen inside the skutterudite material. Indeed, the oxidation of ytterbium produces $\mathrm{Yb}_{2} \mathrm{O}_{3}$ whose coefficient of thermal expansion is more than three times lower than that of $\mathrm{Sb}_{2} \mathrm{O}_{3}{ }^{[14]}$ The corresponding mismatch induces mechanical stress and the formation of microcracks inside the oxide layer. These cracks promote the transport of oxygen and antimony through the oxide layer, further deteriorating the skutterudite material.

The cross-section SEM images of $\mathrm{Yb}_{0.2} \mathrm{Co}_{4} \mathrm{Sb}_{12}$ oxidized at $800 \mathrm{~K}$ are presented in Figure 6. They show a

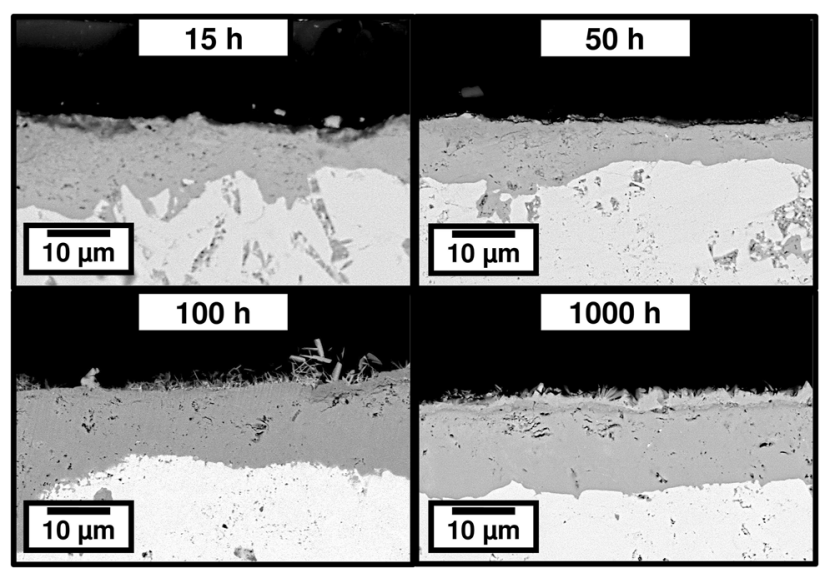

Fig. 6-Cross-section SEM images (backscattered electrons) of $\mathrm{Yb}_{0.2} \mathrm{Co}_{4} \mathrm{Sb}_{12}$ as a function of oxidation time in air at $800 \mathrm{~K}$.

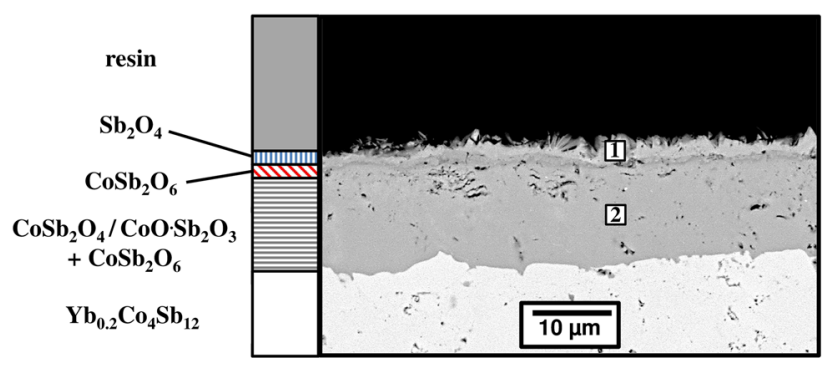

Fig. 7-Cross-section SEM image (backscattered electrons) of $\mathrm{Yb}_{0.2} \mathrm{Co}_{4} \mathrm{Sb}_{12}$ after oxidation in air at $800 \mathrm{~K}$ for $1000 \mathrm{~h}$.

typical contrast of a surface oxide layer on a metallic substrate. Regardless of the oxidation duration, the surface oxide layer is mainly made of a mixture of $\mathrm{CoSb}_{2} \mathrm{O}_{4} / \mathrm{CoO} \cdot \mathrm{Sb}_{2} \mathrm{O}_{3}$ and $\mathrm{CoSb}_{2} \mathrm{O}_{6}$, according to the XRD patterns of Figure 1. From 100 hours of oxidation, some needles are observed on the top of the surface oxide layer. The growth of these needles continues until 1000 hours of treatment, forming a thin light grey layer. This top surface layer is related to the growth of the crystallites observed in the surface images and to the new phase observed from 100 hours of oxidation on the XRD patterns of Figure 1, i.e., $\mathrm{Sb}_{2} \mathrm{O}_{4}$.

This assumption is confirmed by the cross-section SEM image of Figure 7 and the corresponding EDS results presented in Figure 8. Spectrum \#1 obtained from the top surface layer only contains two chemical elements, oxygen and antimony, corresponding to the oxide $\mathrm{Sb}_{2} \mathrm{O}_{4}$. Spectrum \#2 obtained in the lower part of the oxide layer shows the elements cobalt, antimony, and oxygen, matching with the identified mixture of $\mathrm{CoSb}_{2} \mathrm{O}_{4} / \mathrm{CoO} \cdot \mathrm{Sb}_{2} \mathrm{O}_{3}$ and $\mathrm{CoSb}_{2} \mathrm{O}_{6}$. It is noticeable that spectrum \#2 also detects a low amount of ytterbium representative of the inward growth of this mixture of oxides. ${ }^{[35]}$ The oxidation of $\mathrm{Yb}_{0.2} \mathrm{Co}_{4} \mathrm{Sb}_{12}$ seems similar to that of the skutterudite materials of the $\mathrm{CoSb}_{3}$ family, producing a surface oxide layer divided into two parts. The upper part is made of a mixture of antimony oxides 

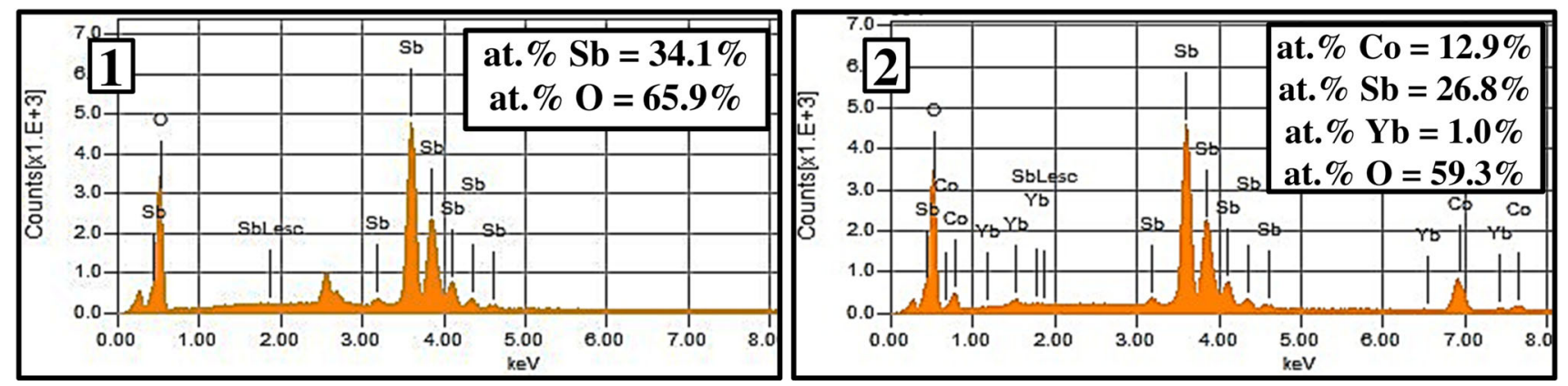

Fig. 8-EDS characterizations of the cross-section of $\mathrm{Yb}_{0.2} \mathrm{Co}_{4} \mathrm{Sb}_{12}$ after oxidation in air at $800 \mathrm{~K}$ for $1000 \mathrm{~h}$ (the corresponding positions are pointed in Fig. 7).
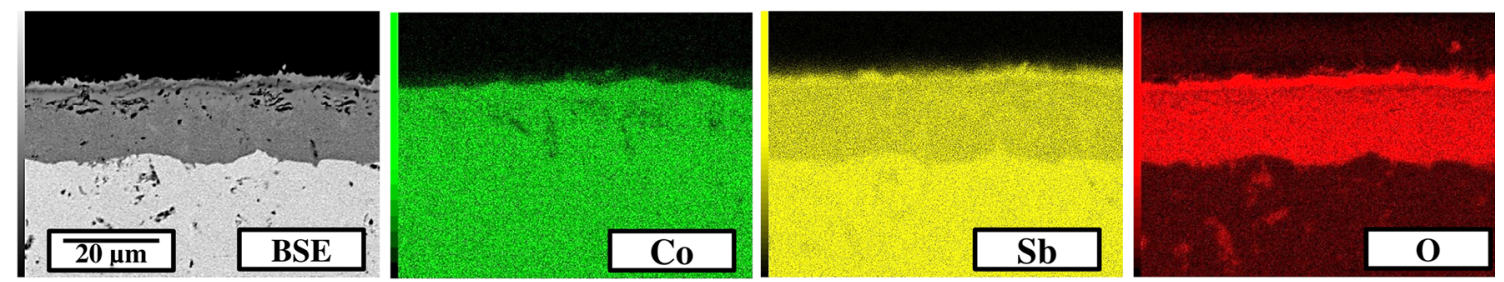

Fig. 9-X-ray elemental mapping of the cross-section of $\mathrm{Yb}_{0.2} \mathrm{Co}_{4} \mathrm{Sb}_{12}$ after oxidation in air at $800 \mathrm{~K}$ for $1000 \mathrm{~h}$.

growing outwards and the lower part is made of a mixture of cobalt antimonates growing inwards. ${ }^{[36]}$

At last, an intermediate thin dark grey layer is present at the interface between these two oxide layers. This intermediate layer is too thin for an accurate EDS characterization. However, the XRD pattern of Figure 1 indicates a strong signal of $\mathrm{CoSb}_{2} \mathrm{O}_{6}$ after 1000 hours of oxidation treatment in comparison with the shortest oxidation durations. Consequently, this layer is undoubtedly made of $\mathrm{CoSb}_{2} \mathrm{O}_{6}$ formed at the last step of the oxidation process as a result of a secondary oxidation reaction. According to Godlewska et al., this interface reaction is promoted by the diffusion of oxygen through the upper oxide layer of $\mathrm{Sb}_{2} \mathrm{O}_{4}$ to reach the lower oxide layer to react with $\mathrm{CoSb}_{2} \mathrm{O}_{4}$ $\mathrm{CoO} \cdot \mathrm{Sb}_{2} \mathrm{O}_{3} \cdot{ }^{[26]}$

The X-ray elemental mapping of Figure 9 confirms the homogeneous elemental distribution within each part of the oxide layer.

For comparison, the cross-section SEM images obtained for $\mathrm{CoSb}_{3}$ are presented in Figure 10. The images show similar contrasts to those previously observed for $\mathrm{Yb}_{0.2} \mathrm{Co}_{4} \mathrm{Sb}_{12}$. However, during the first times of oxidation (15 and 50 hours), the homogeneous surface layer is only composed of the spinel oxide $\mathrm{CoSb}_{2} \mathrm{O}_{4} / \mathrm{CoO} \cdot \mathrm{Sb}_{2} \mathrm{O}_{3}$ according to the XRD patterns of Figure 2. The formation of the top surface layer made of $\mathrm{Sb}_{2} \mathrm{O}_{4}$ and the formation of the intermediate layer made of $\mathrm{CoSb}_{2} \mathrm{O}_{6}$ start from 100 hours of oxidation and continue until 1000 hours of treatment. In that case, $\mathrm{CoSb}_{2} \mathrm{O}_{6}$ is only formed at the interface of the two other oxide layers as a result of the secondary oxidation reaction. ${ }^{[26]}$ Moreover, it is noticeable that the thicknesses of the oxide layers are not the same for $\mathrm{Yb}_{0.2} \mathrm{Co}_{4} \mathrm{Sb}_{12}$ and $\mathrm{CoSb}_{3}$, despite identical experimental conditions.

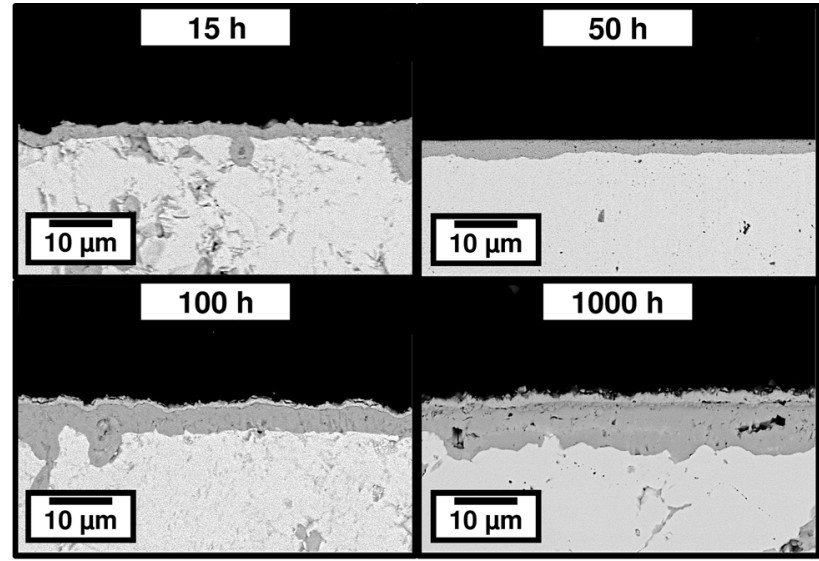

Fig. 10 - Cross-section SEM images (backscattered electrons) of $\mathrm{CoS}_{3}$ as a function of oxidation time in air at $800 \mathrm{~K}$.

The thickness values are plotted for both skutterudites in Figure 11 as a function of the oxidation time. Until 100 hours of oxidation treatment, the thickness of both oxide layers increases quickly but more in the case of $\mathrm{Yb}_{0.2} \mathrm{Co}_{4} \mathrm{Sb}_{12}$, reaching a value thrice that of $\mathrm{CoSb}_{3}$. Next, both thickness variations are low until 1000 hours of oxidation treatment. The thickness of the oxide layer formed on $\mathrm{CoSb}_{3}$ slightly increases, whereas the mass of the sample slightly decreases as shown in Figure 5. This observation means that, after 100 hours of treatment, the oxidation process of $\mathrm{CoSb}_{3}$ is slowed down and the evaporation of chemical species becomes faster than the formation of oxides. On the other hand, the thickness of the oxide layer formed on $\mathrm{Yb}_{0.2} \mathrm{Co}_{4} \mathrm{Sb}_{12}$ remains constant, whereas the mass of the sample continues to increase. This could be a result of the formation of $\mathrm{CoSb}_{2} \mathrm{O}_{6}$ whose diffraction peaks become higher after 


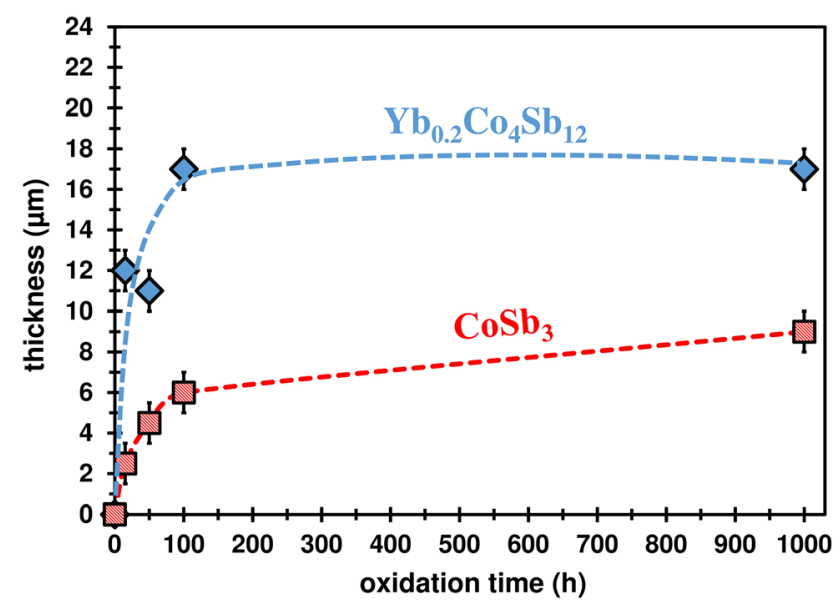

Fig. 11-Thickness of the surface oxide layer of $\mathrm{Yb}_{0.2} \mathrm{Co}_{4} \mathrm{Sb}_{12}$ and $\mathrm{CoSb}_{3}$ as a function of oxidation time in air at $800 \mathrm{~K}$.

1000 hours of oxidation in the case of $\mathrm{Yb}_{0.2} \mathrm{Co}_{4} \mathrm{Sb}_{12}$ (Figure 1). According to reaction (3), $\mathrm{CoSb}_{2} \mathrm{O}_{6}$ is produced by the incorporation of oxygen inside the layer to react with $\mathrm{CoSb}_{2} \mathrm{O}_{4}$. Therefore, the mass of the sample increases without any impact on the thickness of the oxide layer. ${ }^{[27]}$ This observation means that the small amount of ytterbium and the corresponding crystal lattice distortion continue to promote the incorporation of oxygen inside the material, even after 1000 hours of oxidation treatment.

Similarly, Xia et al. note that the filling atom destabilizes the crystal structure of the skutterudite materials, weakening the bonding that is easily broken in oxidizing atmospheres. ${ }^{[14]}$ Therefore, the lifespan of the skutterudite material is slightly reduced but remains reasonable for thermoelectric applications. To mitigate this negative impact, surface protection from a coating could be considered. For example, a metallic coating made of aluminide is established to be an efficient oxidation protection for skutterudite materials. ${ }^{[22]}$ Besides, the skutterudite material $\mathrm{Yb}_{0.2} \mathrm{Co}_{4} \mathrm{Sb}_{12}$ has powerful thermoelectrical properties and demonstrates a great interest for industrial applications in oxidizing environments.

\section{CONCLUSIONS}

This work describes the oxidation behavior of $\mathrm{Yb}_{0.2} \mathrm{Co}_{4} \mathrm{Sb}_{12}$ in air at $800 \mathrm{~K}$ for $15,50,100$, and 1000 hours. An oxide layer made of several phases is progressively formed on the surface of the skutterudite material. The oxidation treatment induces a combination of both the formation and volatilization of various oxides, impacting the mass variation of the skutterudite material and the thickness of the formed oxide layer. The presence of ytterbium makes the skutterudite more oxidized because of the promotion of oxygen diffusion throughout the crystal lattice. Nevertheless, the impact on the oxidation degradation is moderate and $\mathrm{Yb}_{0.2} \mathrm{Co}_{4} \mathrm{Sb}_{12}$ remains an interesting thermoelectrical material usable under oxidizing environments. Surface protection with a metallic coating made of aluminide would be an interesting perspective to extend the lifespan of the skutterudite material.

\section{ACKNOWLEDGMENTS}

The French National Research Agency (ANR) is gratefully acknowledged for the financial support of the Nanoskut Project (ANR-12-PRGE-0008-01).

\section{REFERENCES}

1. M. Rull-Bravo, A. Moure, J.F. Fernandez, and M. Martin-Gonzalez: RSC Adv., 2015, vol. 5, pp. 41653-67.

2. G. Rogl and P. Rogl: Curr. Opin. Green Sustain. Chem., 2017, vol. 4, pp. 50-7.

3. R. Drevet, L. Aranda, C. Petitjean, N. David, D. Veys-Renaux, and P. Berthod: Oxid. Met., 2019, vol. 91, pp. 767-79.

4. W. Liu, Q. Jie, H.S. Kim, and Z. Ren: Acta Mater., 2015, vol. 87, pp. $357-76$

5. M. Zebarjadi, K. Esfarjani, M.S. Dresselhaus, Z.F. Ren, and G. Chen: Energy Environ. Sci., 2012, vol. 5, pp. 5147-62.

6. J.W. Sharp, E.C. Jones, R.K. Williams, P.M. Martin, and B.C. Sales: J. Appl. Phys., 1995, vol. 78, pp. 1013-18.

7. J.X. Zhang, Q.M. Lu, K.G. Liu, L. Zhang, and M.L. Zhou: Mater. Lett., 2004, vol. 58, pp. 1981-84.

8. Y. Kawaharada, K. Kurosaki, M. Uno, and S. Yamanaka: J. Alloys Compd., 2001, vol. 315, pp. 193-97.

9. R. Guo, X. Wang, and B. Huang: Sci. Rep., 2015, vol. 5, p. 7806.

10. X. Shi, J. Yang, J.R. Salvador, M. Chi, J.Y. Cho, H. Wang, S. Bai, J. Yang, W. Zhang, and L. Chen: Multiple-Filled SkutteruditesJ. Am. Chem. Soc., 2011, vol. 133, pp. 7837-46.

11. E. Alleno, E. Zehani, and O. Rouleau: J. Alloys Compd., 2013, vol. 572, pp. 43-48.

12. E. Alleno, E. Zehani, M. Gaborit, V. Orodniichuk, B. Lenoir, and M. Benyahia: J. Alloys Compd., 2017, vol. 692, pp. 676-86.

13. T. Dahal, Q. Jie, G. Joshi, S. Chen, C. Guo, Y. Lan, and Z. Ren: Acta Mater., 2014, vol. 75, pp. 316-21.

14. X. Xia, P. Qiu, X. Shi, X. Li, X. Huang, and L. Chen: J. Electron. Mater., 2012, vol. 41, pp. 2225-31.

15. I.K. Dimitrov, M.E. Manley, and S. Shapiro: Phys. Rev. B, 2010, vol. 82 , p. 174301

16. J. Yang, Q. Hao, H. Wang, Y.C. Lan, Q.Y. He, A.J. Minnich, D.Z. Wang, J.A. Harriman, V.M. Varki, M. Dresselhaus, G. Chen, and Z.F. Ren: Phys. Rev. B, 2009, vol. 80, p. 115329.

17. L.E. Bell: Science, 2008, vol. 321, pp. 1457-61.

18. V. Andrei, K. Bethke, and K. Rademann: Energy Environ. Sci., 2016, vol. 9, pp. 1528-32.

19. R. Drevet, L. Aranda, C. Petitjean, D. Veys-Renaux, N. David, and P. Berthod: Oxid. Met., 2020, vol. 93, pp. 559-72.

20. R. Kühn, O. Koeppen, P. Schulze, and D. Jänsch: Mater. Today proc., 2015, vol. 2, pp. 761-69.

21. D. Veys-Renaux, R. Drevet, C. Petitjean, L. Aranda, N. David, and P. Berthod: J. Solid State Electrochem., 2018, vol. 22, pp. 2821-28.

22. R. Drevet, C. Petitjean, N. David, L. Aranda, D. Veys-Renaux, and P. Berthod: Mater. Chem. Phys., 2020, vol. 241, p. 122417.

23. R. Drevet, L. Aranda, N. David, C. Petitjean, D. Veys-Renaux, and P. Berthod: Surf. Coat. Technol., 2020, vol. 385, p. 125401.

24. A. Navrotsky and O.J. Kleppa: J. Inorg. Nucl. Chem., 1968, vol. 30, pp. 479-98.

25. H.SC.. O'Neill and A. Navrotsky: Am. Mineral., 1983, vol. 68, pp. 181-94.

26. E. Godlewska, K. Zawadzka, A. Adamczyk, M. Mitoraj, and K. Mars: Oxid. Met., 2010, vol. 74, pp. 113-24.

27. J. Leszczynski, K.T. Wojciechowski, and A.L. Malecki: J. Therm. Anal. Calorim., 2011, vol. 105, pp. 211-22.

28. M.K. Kumawat, C. Parlikar, M.D. Zafir Alam, and D.K. Das: Metall. Mater. Trans. A, 2021, vol. 52A, pp. 378-93. 
29. E. Mohammadi Zahrani and A.M. Alfantazi: Metall. Mater. Trans. A, 2013, vol. 44A, pp. 4671-99.

30. W.J. Zhang and R. Sharghi-Moshtaghin: Metall. Mater. Trans. A, 2021, vol. 52A, pp. 1492-1502.

31. R. Hara, S. Inoue, H.T. Kaibe, and S. Sano: J. Alloys Compd., 2003, vol. 349, pp. 297-301.

32. M. Ritouet and P. Berthod: Oxid. Met., 2018, vol. 89, pp. 339-55.

33. F. Wu, Q. He, D. Hu, F. Gao, H. Song, J. Jia, and X. Hu: J. Electron. Mater., 2013, vol. 42, pp. 2574-81.
34. W.L. Bragg: Philos. Mag., 1920, vol. 40, pp. 169-89.

35. P. Berthod and Z. Himeur: Oxid. Met., 2018, vol. 90, pp. 187-202.

36. V. Savchuk, A. Boulouz, S. Chakraborty, J. Schumann, and H. Vinzelberg: J. Appl. Phys., 2002, vol. 92, pp. 5319-26.

Publisher's Note Springer Nature remains neutral with regard to jurisdictional claims in published maps and institutional affiliations. 